\title{
EVALUASI PELAKSANAAN PROGRAM ELIMINASI MALARIA DI KABUPATEN ACEH SINGKIL TAHUN 2018
}

\author{
Afriadi $^{1}$, Razia Begum Suroyo ${ }^{2}$, Juliandi Haharap ${ }^{3}$ \\ ${ }^{1}$ Program Studi S2 Ilmu Kesehatan Masyarakat, Institut Kesehatan Helvetia \\ ${ }^{2,3}$ Fakultas Kesehatan Masyarakat, Institut Kesehatan Helvetia \\ ${ }^{3}$ Fakultas Kedokteran, Universitas Sumatera Utara \\ Email: afriadipridi@ymail.com; razia.begum@helvetia.ac.id; juliandiharahap@yahoo.com
}

\begin{abstract}
The success of the malaria elimination program in Kabuupaten Aceh Singkil, the Annual Parasite Incident (API) per 1000 population will reach 0\%. Nowadays, the frequency of implementing the program has decreased so that it is suspected that it can cause people to suffer from malaria. The purpose of the study was to analyze the evaluation of the implementation of the malaria elimination program. This type of research is qualitative. The informants consisted of 5 key informants namely the person in charge of $P 2 P$, malaria management officers, village midwives and 4 main informants namely the head of the puskesmas and village head and 6 additional informants namely the community, pregnant women, cadres. Data were analyzed by interactive methods through the stages of data reduction, presentation and drawing conclusions. The results showed that blood tests were not carried out unless the community had a fever. Distribution of delivery nets, screening for pregnant women is reduced, and biological vector control is not monitored. Epidemiological surveillance and epidemic prevention are not carried out because there are no outbreaks so monitors are made in the form of monthly reports. Educational activities in the form of outreach continue to the present and responsibilities are more focused on village midwives/cadres. Training and guidance activities for officers have never been done. The percentage of API reaches $0 \%$ in 2018. It is recommended that health workers remain vigilant and prioritize programs supporting malaria elimination programs along with other health programs through community empowerment today.
\end{abstract}

\section{Keywords: evaluation, implementation, malaria elimination, program}

\section{PENDAHULUAN}

Program eliminasi malaria adalah suatu upaya untuk menghentikan penularan malaria. World Health Organization (WHO) memperkirakan 228 juta kasus malaria terjadi di seluruh dunia tahun 2018 dan sekitar 405.000 orang meninggal karena penyakit tersebut. Kasus tertinggi terjadi di Afrika sub-Sahara (213 juta atau 93\%), diikuti oleh wilayah Asia Tenggara 3,4\% kasus dan Mediterania Timur 2,1\% kasus (WHO, 2019).

Secara nasional, $75-80 \%$ kasus malaria berasal dari kawasan Indonesia
Timur (Papua, Papua Barat, Maluku, Maluku Utara dan NTT). Malaria di NTT tertinggi kedua, dimana tahun 2006 sebanyak 123,848 kasus; menurun menjadi 36,128 di tahun 2015. Annual Parasite Incident (API) juga menurun dari 28.3 per 1000 menjadi 7.1 per 1000 dalam kurun waktu sama (Selasa, 2017).

Jumlah penderita malaria positif di Provinsi Aceh tahun 2016 yang dilaporkan sebanyak 422 kasus dengan API sebesar 0,1. Terjadi penurunan jumlah kasus tahun 2015 dibandingkan tahun 2014 sebanyak 909 kasus dengan API sebesar 0,2 (Aceh, 2015). 
Hasil evaluasi Bidang Pencegahan dan Pengendalian Penyakit (P2P) Dinas Kabupaten Singkil, Persentase API 2013 yaitu (1,5\%) (15 kasus tidak ada meninggal dunia), tahun 2014 (1,9\%) (13 kasus tidak ada meninggal dunia). Selanjutnya tahun 2015 yaitu $0 \%$, tahun 2016 yaitu 0\% dan tahun 2017 telah mencapai 0\%. Kabupaten Aceh Singkil tahun 2017 mendapat sertifikasi Malaria dari Kementerian Kesehatan Republik Indonesia (Singkil, 2018).

Keberhasilan eliminasi malaria tidak terlepas dari dukungan dana bersumber dana. Pengucuran dana pencegahan malaria sudah sejak lama dimulai tahun 2013 sebesar Rp. 987 juta, 2014 sebesar Rp. 995, tahun 2015 sebesar 873 juta, tahun 2016 sebesar Rp. 860 juta, tahun 2017 sebesar Rp. 856 juta, tahun 2018 sebesar Rp. 315 juta dan tahun 2019 hanya mencapai 125 juta.

Hasil pengamatan peneliti bahwa di berbagai daerah di Kabupaten Aceh Singkil memiliki berbagai penyakit menular seperti 135 kasus TBC, 0,23\% kusta dari 10.000 penduduk, dan $47 \%$ filariasis per 100.000 penduduk, sedangkan malaria 0\%. Hal ini dapat dijelaskan bahwa kasus penyakit menular masih cukup tinggi terjadi disebabkan pencegahan dan pengendalian belum berjalan efektif dibandingkan dengan pengelolaan malaria.
Selain itu, kebiasaan masyarakat pada hari Jumat untuk bergotong royong (Jumat Bersih) tidak lagi berlangsung secara rutin di daerah endemis seperti Desa Teluk Nibung dan Desa Kuala Baru Laut. Frekuensi penyuluhan kepada masyarakat di beberapa daerah terkesan berkurang sehingga dapat menyebabkan pemahaman petugas akan berkurang dalam menguasai materi tentang program eliminasi malaria. Saat ini petugas juga merasa bahwa peningkatan pemahaman masyarakat tentang program eliminasi sudah cukup sehingga frekuensi penyuluhan berkurang.

Setelah program eliminasi berjalan selama 2 tahun, petugas jarang melakukan pemantauan jentik di lingkungan masyarakat diduga disebabkan kurangnya motivasi petugas sehingga penyampaikan informasi juga berkurang kepada masyarakat. Pertemuan antara lintas sektoral hanya diselenggarakan setiap tahun saja untuk mengetahui evaluasi program eliminasi malaria karena terbatasnya dana dari Dinas Kesehatan Kabupaten Aceh Singkil. Alasan inilah yang membuat peneliti tertarik mengkaji tentang evaluasi program eliminsasi malaria.

\section{METODE}

Jenis penelitian ini adalah penelitian kualitatif dengan menggunakan fenomenologi. Informan penelitian 
terbagi atas 5 informan kunci yaitu penanggung jawab P2P, petugas pengelola malaria, bidan desa dan 4 informan utama yaitu kepala puskesmas dan kepala desa serta 6 informan tambahan yaitu masyarakat, ibu hamil, kader. Pengumpulan data dapat dilakukan dengan observasi dan wawancara secara mendalam kepada informan. Data yang dianalisis menggunakan metode interaktif melalui tahapan reduksi data, penyajian dan penarikan kesimpulan.

\section{HASIL DAN PEMBAHASAN}

\section{Karakteristik}

Informan kunci 5 orang terdiri dari 1 orang penanggung jawab program P2P tugas pokok mengelola program eliminasi malaria di Dinas Kesehatan Aceh Singkil, 2 orang pertugas pengelola P2P malaria setiap Puskesmas di Kecamatan Pulau Banyak dan Kuala Baru sebagai pelaksana harian melakukan kegiatan program eliminasi malaria.

Informan berumur 28 sampai dengan 36 tahun dan berstatus telah menikah. Semua perempuan kecuali penanggung jawab program P2P dengan latar belakang pendidikan formal Strata 1 (S1) dan Diploma 3 (D3). Informan telah bekerja 3 sampai 4 tahun. Semuanya informan bertempat tinggal di Kota Singkil.
Informan utama 4 orang terdiri dari 2 orang kepala puskesmas sebagai penangung jawab program eliminasi malaria di wilayah kerjanya dan 2 orang kepala desa bertugas mewujudkan desanya bebas dari malaria dengan bekerjasama dengan puskesmas dan dinas. Informan utama semua laki-laki kecuali Kepala puskesmas Kecamatan Kuala Baru. Informan telah bekerja 2 sampai 4 tahun. Semuanya Informan bertempat tinggal di Kota Singkil.

Selanjutnya informan triangulasi 6 orang terdiri dari dari 2 orang masyarakat, 2 orang ibu hamil dan 2 orang kader. Informan kader bertugas membantu petugas puskesmas dan dinas untuk mewujukkan program eliminasi malaria di wilayah kerjanya. Informan kader telah bekerja cukup lama 6 sampai 7 tahun dan semuanya bertempat tinggal di Desa Teluk Nibung dan Kuala Baru Laut.

\section{Input}

Kecukupan dan pembagian tugas sumber daya manusia

Petugas yang terlibat dalam eliminasi malaria adalah kepala dinas, kepala bidang Program P2P, Kepala seksi P2P, dan Wasor malaria sebagai petugas penanggung jawab malaria. Tingkat puskesmas terdiri dari kepala puskesmas, dokter, analis, pengelola program $\mathrm{P} 2 \mathrm{P}$, petugas pencatat dan pelaporan, bidan dan kader desa. 
Petugas kesehatan yang terkait program eliminasi malaria telah ditetapkan tugas dan tanggung jawab (juknis) masing-masing dan didokumentasikan dan diwajibkan mengikuti sosialisasi.

\section{Ketersediaan sarana dan prasarana}

Ketersediaan sarana dan prasarana sudah memadai untuk mendukung program eliminasi malaria. Wilayah kerja Dinas Kesehatan Kabupaten Singkil yang terdiri dari 11 puskesmas, semuanya memiliki laboratorium mikroskop dan RDT di setiap PMD. Namun kendalanya tidak semua Puskesmas memiliki tenaga ahli analis sehingga diberdayakan petugas lainnya dengan terlebih dahulu dilakukan pelatihan diagnosa malaria

\section{Proses}

\section{Penemuan dan tata laksana penderita}

Pelaksanaan program eliminasi malaria melalui penemuan dan tata laksana penderita berdasarkan pendataan dan pengobatan penderit amalaria.

a. Pendataan penderita malaria berkurang

Pada umumnya $80 \%$ penemuan penderita malaria karena berobat ke puskesmas dan posyandu atapun (PMD), klinik kesehatan dengan gejala mengalami demam tinggi, selanjutnya dilakukan tes darah apakah positif atau negatif. Masyarakat yang positif menderita penyakit malaria akan didata dan dilaporkan ke petugas pencatat dan pelaporan di puskesmas. Berikut hasil wawancara.

Mulai berkurang, Sebelum pre eliminasi malaria, terjun langsung ke lapangan untuk mencari kasus malaria. Saat ini masyarakatnya datang sendiri ke pelayanan kesehatan. (TI, Penanggung jawab P2P)

b. Pengobatan penderita malaria berkurang

Saat ini pengobatan kasus malaria tidak ada lag karena masyarakat penderita juga tidak ada. Berikut hasil wawancara.

Pengobatan malaria tidak ada, Kasus malaria biasanya ditandainya dengan gejala demam tetapi bukan disebabkan nyamuk malaria tetapi karena flu, (Ma, Bidan desa Kuala Baru Laut)

\section{Pencegahan dan penanggulangan faktor resiko}

a. Mendistribusikan kelambu berinsektisida berkurang

Pendistribusian kelambu berinsektisida secara massal dilakukan di awal program malaria. Saat ini kegiatan tersebut tidak dilakukan lagi di daerah endemis karena kasus malaria sudah dapat ditanggulangi. Berikut hasil wawancara.

Tidak dibagi lagi, pendistribusian kelambu khusus bagi positif penderita malaria saja untuk mencegah tidak tertular, masyarakat lainnya tidak dibagi lagi. (KE, Pengelola program Malari Kec. Kuala Baru)

b. Penyemprotan lingkungan rumah berkurang

Kegiataan penyemprotan dilakukan dengan frekuensi terbatas selama 2 tahun terakhir hanya 1 kali saja setahun 
sekarang ini. Kegiatan penyemportan dilakukan radius 200 meter dari rumah penderita. Namun berbeda dengan ungkapan informan lainnya mengatakan bahwa penyemprotan tidak dilakukan sampai 200 meter tetapi beberapa rumah di sekitar rumah penderita untuk mencegah agar vektor nyamuk tidak berkembang. Berikut hasil wawancara.

Ada tetapi jarang, kalau tak salah, tahun semalam ada di semprot, kalau sekarang tidak ada. (RM, Ibu hamil desa Teluk Nibung)

c. Pengendalian vektor hayati tidak optimal

Upaya pengendalian vektor di lingkungan sekitar masyarakat dengan menaman berbagai tumbuhan yang tidak disukai nyamuk seperti bunga tahi kuning, bunga lavender dan sereh wangi. Respon masyarakat ada yang mendukung dan ada yang tidak mendukung karena susah merawatnya dan tidak sempat untuk mengurus tanaman tersebut. Berikut hasil wawancara.

Masyarakat kurang peduli, tugas saya menganjurkan masyarakat menaman tanaman yang ditakuti nyamuk seperti bunga lavender, sereh wangi sekaligus menjaga kebersihan lingkungan rumah tetapi sebagian kecil yang menanam. (NA, Pengelola program Malari Kec. Pulau Banyak)

d. Skrining ibu hamil berkurang

Kegiatan skrining ibu hamil sampai saat ini masih dilakukan namun frekuensi mulai menurun. Hal ini disebabkan takut dan merasa cemas kalau diambil darahnya. Disisi lain, petugas juga tidak ingin memaksa masyarakat khususnya ibu hamil ditest darahnya. Kegiatan skrining dilakukan pada saat memeriksa kesehatan ataupun mengikuti kegiatan di Posyandu. Berikut hasil wawancara.

Ibu hamil periksa darah ke puskesmas sekalian periksa kehamilan, sekarang tidak ada lagi pemeriksa darah, sakit juga kalau tidak periksa diambil darahnya. (U, Masyarakat desa Kuala Baru Laut)

\section{Kegiatan surveilans epidemiologi dan penanggulangan wabah}

Kegiatan surveilans epidemiologi dan penanggulangan wabah tidak diselenggarakan karena wabah malaria sudah tidak terjadi khususnya di daerah endemis. Namun demikian pengendalian malaria dengan membuat laporan bulanan, mulai dari desa, puskesmas yang disampaikan ke dinis setiap bulan.

Berikut hasil wawancara.

Kegiatan surveilans tidak ada dan penanggulangan berbentuk laporan, kita menunggu laporan dari masing-masing puskesmas masih berjalan setiap bulan sebagai bahan evaluasi dalam mempertahankan eliminasi malaria. (TI, Penanggung jawab $P 2 P$ )

\section{Peningkatan KIE}

a. Penyuluhan berfokus pada bidan/kader dan papan waspada malaria tidak direnovasi

Setelah memperoleh Sertifikasi tahun 2017, kegiatan penyuluhan tidak pernah dilakukan lagi sampai saat ini oleh bidan dan kader desa. Mereka sebagai 
pemegang kunci dalam kegiatan promosi kesehatan di masyarakat karena setiap bulan petugas menyelenggarakan kegiatan Posyandu dan program kesehatan lainnya. Sarana penyuluhan berupa papan waspada malaria yang ditempatkan di puskesmas dan PMD tidak diperbaharui lagi. Berikut hasil wawancara.

Kegiatan penyuluhan dititikberat kan keapda para bidan desal kader. Mereka memberikan penyuluhan untuk meningkatkan kesehatan masyarakat. Untuk papan sudah setahun lebih tidak ganti. (NA, Pengelola program Malari Kec. Pulau Banyak)

b. Kemitraan/koordinasi setiap akhir tahun

Pertemuan dengan mitra diselenggarakan setiap akhir tahun. Kegiatan tersebut dibuat untuk melihat hasil program elminasi malaria. Berikut hasil wawancara.

Pertemuan koordinasi sudah berkurang, Saya beserta pengelola $\quad P 2 P \quad$ mengikuti pertemuan setiap akhir tahun. (H, Kapus Kec. Pulau Banyak)

\section{Peningkatan sumber daya manusia}

Kegiatan peningkatan sumber daya manusia saat ini tidak diselenggarakan lagi. Dinas kesehatan menyelenggarakan kegiatan pelatihan tentang tanda-tanda gejala menderita malaria kepada petugas. Berikut hasil wawancara.

Tidak ada, kami sudah pernah dilatih dan diberikan sosialisasi, sekarang ngak ada. (NA, Pengelola program Malari Kec. Pulau Banyak)

Berdasarkan hasil wawancara diperoleh tema dan subtema dalam penelitian sebagai berikut.

\section{Tabel 1. Identifikasi Teman dan Sub Tema Penelitian}

\begin{tabular}{ll}
\hline \multicolumn{1}{c}{ Tema } & \multicolumn{1}{c}{ Sub tema } \\
\hline $\begin{array}{l}\text { Penemuan dan tata laksana } \\
\text { penderita }\end{array}$ & $\begin{array}{l}\text { Pendataan penderita malaria berkurang } \\
\text { Pencegahan dan } \\
\text { penanggulangan faktor resikonderita malaria berkurang } \\
\text { Mendistribusikan kelambu berinsektisida berkurang } \\
\text { Penyemprotan lingkungan rumah berkurang } \\
\text { Pengendalian vektor hayati tidak optimal } \\
\text { Skrining ibu hamil berkurang }\end{array}$ \\
$\begin{array}{l}\text { Kegiatan surveilans } \\
\text { epidemiologi dan } \\
\text { penanggulangan wabah }\end{array}$ & Penyampaian laporan bulanan \\
$\begin{array}{l}\text { Peningkatan KIE } \\
\text { Peningkatan sumber daya } \\
\text { manusia }\end{array}$ & $\begin{array}{l}\text { Penyuluhan berfokus pada bidan/kader dan papan } \\
\text { waspada malaria tidak direnovasi } \\
\text { Kemitraan/koordinasi setiap akhir tahun } \\
\text { Kegiatan pelatihan/ sosialisasi tidak diselenggarakan }\end{array}$ \\
\hline
\end{tabular}

\section{Output}

Hasil evaluasi Bidang Pencegahan dan Pengendalian Penyakit (P2P), API per 1000 penduduk tahun 2018 yaitu
$0 \%$. Keberhasilan ini, membuat daerah Kabupaten Aceh Singkil tahun 2017 mendapat sertifikasi Malaria dari Kementerian Kesehatan Republik 
Indonesia berdasarkan hasil suvei dari Tim kementerian kesehatan dan United Nations International Children's Emergency Fund (UNICEF).

Berdasarkan hasil penelitian di atas berupa input, proses dan output, maka dapat dianalisis temuan tersebut sebagai berikut.

\section{Input dalam Evaluasi Pelaksanaan Program Eliminasi Malaria}

\section{Tenaga kesehatan}

Tenaga kesehatan yang terlibat dalam program eliminasi telah mendapatkan pembagian tugas masing-masing yang disesuaikan dengan jumlah tenaga kesehatan. Tenaga kesehatan yang terlibat dalam program tersebut dapat memiliki dua tugas sekaligus, seperti petugas pencatatan dan pelaporan sekaligus bertugas sebagai petugas pemegang program $\mathrm{P} 2 \mathrm{P}$ malaria.

Menurut Kemenkes (2013), salah satu upaya untuk upaya meningkatkan kompetensi pelaksana program dapat dilakukan melalu pelatihan.

Tenaga kesehatan sudah memiliki kompetensi profesi yang baik, ditinjau dari pengetahuan teknis keprofesian masing-masing maupun dalam menjalankan tugas dan tanggung jawabnya masing-masing dalam pelaksanaan program eliminasi malaria.

Tenaga keseahtan telah mendapatkan pelatihan dan kegiatan sosialisasi diterapkan pada awal penggalakkan program malaria.

\section{Sarana prasarana/informasi}

Sarana dan prasarana dalam pelaksanaan program eliminasi malaria yang tersedia yaitu, RDT, mikroskop dan alat kesehatan yang digunakan untuk pemeriksaan sediaan darah. Sarana logistik lainnya adalah ketersediaan obat anti malaria yang mendukung sistem pelaksanaan program eliminasi malaria sudah cukup lengkap. Adapun obat anti malaria yang tersedia di Kabupaten Aceh Singkil adalah ACT dan primakuin, selain itu juga tersedia dopsisiclin.

Menurut Kemenkes (2014), pengobatan malaria yang telah dianjurkan oleh program saat ini adalah dengan ACT (Artemisinin based Combination Therapy) ditambah dengan Primakuin. Kelambu disediakan oleh dinas kesehatan setempat.

\section{Proses}

\section{Penemuan dan Tatalaksana Penderita}

Pada pre eleminasi malaria, kegiatan pemeriksaan darah pasien yang berobat ke puskesmas diperiksa secara rutin. Tenaga kesehatan menganjurkan agar pasien diperiksa darahnya untuk mengetahui gejala malaria ataupun penyakit lainnya. Perlakuan khusus diberikan kepada ibu hamil yang diwajibkan atasnya untuk mengetahui kondisi kesehatannya. Demikian juga masyarakat yang bertempat tinggal jauh dari desa dapat melakukan pemeriksaan 
darah di posyandu atau PMD dengan menggunakan RDT.

Menurut Kemenkes (2013) bahwa penemuan dan tatalaksana penderita dapat dilakukan melalui pemeriksaan darah di fasilitas kesehatan. Diperkuat dengan penelitian Selasa (2017) menunjukkan hasil bahwa penemuan dan tatalaksana penderitadi Puskesmas sekota Kupang dilaksanakan sesuai kebijakan yang ditetapkan yaitu mencapai $100 \%$ untuk 11 Puskesmas.

Setelah mendapatkan sertifikasi malaria, kegiatan penemuan dan tata laksana penderita mulai berkurang. Kegiatan pemeriksaan darah masyarakat tidak rutin lagi. Masyarakat hanya memeriksa darah bila mengalami gejala deman, ngilu dan nyeri untuk mengetahui apakah darahnya mengandung plasmodium, (positif menderita malaria). Adapun alasan karena Kabupaten Aceh Singkil memasuki tahap pemelihraan agar masyarakat tidak terlular penyakit malaria lagi (API 0\%).

Upaya lebih difokuskan kepada mengendalikan penyebaran vektor nyamun melalui pencegahan dan pengendalian faktor risiko seperti menjaga kebersihan lingkungan, pengendalian secara hayati dengan menaman tamanan yang tidak disukai nyamuk dan skrining ibu hamil serta pendistribusian kelambu berinsektisida agar tidak gigit nyamuk sewaktu tidur pada malam hari.

Menurut Laihad dan Harijanto (2011) pengobatan yang dianjurkan adalah pengobatan yang efektif, radikal, membunuh semua stadium parasit yang ada di dalam tubuh. Tujuan pengobatan untuk penyembuhan klinis, parasitologi dan memutuskan mata rantai penularan.

\section{Pencegahan dan Penanggulangan Faktor Resiko}

Kegiatan pendistribusian kelambu berinsektisida berlangsung untuk mengurangi kasus malaria. Selama periode tahun 2015-2017 pencapaian angka API yaitu 0\%, Namun pada tahun 2018 kegiatan pendistribusian kelambu berinsektisida tidak dilakukan lagi.

Sesuai dengan penelitian Renwarin, Kandou, dan D (2014) mengatakan. pembagian kelambu kepada masyarakat harus dibarengi dengan edukasi yang tepat sesuai dengan tingkat pemahaman masyarakat setempat.

Kegiatan lainnya dalam pencegahan dan pengendalian faktor risiko dengan melakukan penyemportan lingkungan rumah radius $200 \mathrm{~m}$. Kegiatan penyemprotan rumah berjalan rutin mulai tahun 2014 sampai 2017 oleh petugas kesehatan bersama dengan petugas penyemprot dari masyarakat. Namun setelah tahun 2018 kegiatan tersebut jarang dilakukan karena tidak ditemukan masyarakat menderita penyakit malaria. 
Jarak rumah dengan tempat perindukan nyamuk seperti sawah, dan ladang merupakan faktor risiko penularan malaria karena jarak terbang nyamuk pada kondisi normal adalah maksimal 200 meter (Ngambut \& Sila, 2013).

Pemerintah Kabupaten Aceh Singkil juga menganjurkan pengendalian vektor hayati dengan memberikan penyuluhan tentang manfaaf menanam tanaman yang tidak disukai nyamuk seperti lavender, serei wangi, dan bunga tahi kuning. Respons masyarakat lebih banyak yang tidak melakukannya karena tidak sempat atau sibuk mengurus keluarga. Pengendalian hayati tidak pernah dipantau. Menurut penelitian Salman, Pinontoan, dan Keeknusa (2017) bahwa pengendalian vektor malaria dapat dilakukan dengan menaman tamanan yang ditakuti nyamuk di Kabupaten Halmahera Timuror.

Upaya pengendalian lainnya adalah skrining ibu hamil sudah mulai berkurang. Setiap ibu hamil yang melakukan pemeriksaan kesehatan di posyandu, puskesmas dan fasilitas kesehatan tidak diwajibkan lagi pemeriksan darah untuk mengetahui apakah kondisi kesehatan ibu hamil.

Surveilans Epidemiologi dan Penanggulangan Wabah

Kegiatan surveilans epidemiologi dan penanggulangan wabah tidak diselenggarakan oleh Dinas Kesehatan Kabupaten Aceh Singkil karena wabah malaria sudah tidak terjadi khususnya di daerah endemis. Namun demikian petugas Penanggung Jawab P2P pengendalian malaria dengan membuat laporan bulanan, mulai dari desa, puskesmas yang disampaikan ke dinis setiap bulan. Kegiatan ini masih berlangsung sampai saat ini.

Zaenuddin dan Hendrati (2014) mengatakan bahwa pada tahap proses pengumpulan data menggunakan format laporan mingguan W2 dan format laporan bulanan, format laporan dan alur pelaporan sederhana, kelengkapan laporan W2 dan bulanan 100\%, ketepatan waktu laporan W2 >80\% dan laporan bulanan $>90 \%$.

Bentuk dan penyampaian laporan surveilans epidemiologi sampai saat ini masih dilakukan sesuai dengan peraturan Bupati No. 11 Tahun 2013 bahwa laporan surveilans epidemiologi dan penanggulangan wabah dilakukan rutin setiap satu bulan sekali untuk bahan evaluasi dalam penanggulangan wabah malaria.

Saat ini Kabupaten Aceh Singkil menggalakkan program 3M (Menguras, Menutup, Mengubur) untuk memutus rantai perkembangbiakan nyamuk malaria. Setiap rumah dianjurkan oleh bidan desa dan kader selalu setiap minggu menerapkan program 3M. Bila ada tempat penampungan air yang sulit 
dikuras tenaga kesehatan memberikan larvasida, atau racun larva serangga yang dapat diperoleh di PMD.

Masyarakat Desa Wagirpandan rutin melalui observasi, menguras air dan membersihkan penampungan air di dalam rumah dan di pekarangan rumah masing-masing untuk mengendalikan jentik nyamuk (Irawan, Pujiyanti, \& Trapsilowati, 2014).

Masyarakat juga dianjurkan Perilaku Hidup Bersih dan Sehat (PHBS) guna menghindari gangguan penyakit terutama malaria. Selain kegiatan gotong royong, masyarakat juga dianjurkan membersihkan rumah, tidak menggantung baju dan menghindari pakaian yang bertumpuk-tumpuk untuk menghindari sarang nyamuk tertelur di dalam rumah terutama lawa-lawa dalam atas rumah. Perubahan perilaku masyarakat berlangsung sampai sekarang ini.

\section{Peningkatan Komunikasi Edukasi dan Informasi (KIE)}

Kegiatan penyuluhan oleh kader/bidan desa pun sudah mulai berkurang karena berkaitan dengan banyaknya program kesehatan lainnya yang dijalankan untuk meningkatkan derajat kesehatan masyarakat seperti Program KIA meliputi gizi buruk stunting, kesehatan ibu dan anak. Selain itu kepala desa juga memberdayakan tokoh pemuda dan masyarakat/ agama ikut serta mengkam-panyekan program malaria.
Sesuai penelitian Akay, Tuda, dan Pijoh (2015) menjelaskan kegiatan penyuluhan belum optimal di Kecamatan Silian Raya Kabupaten Minahasa Tenggara. Diupayakan agar kegiatan penyuluhan tetap dilakukan secara rutin terutama informasi baru tentang malaria kepada masyarakat

Demikian juga kegiatan koordinasi pelaksanaan program eliminasi malaria mengalami penurunan. Pertemuan dengan mitra tersebut diselenggarakan setiap akhir tahun saja untuk melihat hasil program elminasi malaria. Pengurangan frekuensi pertemuan tersebut dikurangi disebabkan wilayah kerja Kabupaten Aceh Singkil telah memasuki tahap pemeliharaan dalam program eliminasi malaria.

Sesuai dengan penelitian Rogayah et al.(2015) bahwa pertemuan perugas melakukan evaluasi diselenggarakan tiap tahun untuk memantau perkembangan perkembangan Malaria di Kota Banjarbaru Provinsi Kalimantan Selatan

\section{Peningkatan sumber daya manusia}

Kegiatan peningkatan sumber daya manusia melalui pelatihan tentang tanda-tanda gejala menderita malaria kepada petugas malaria dimulai awal tahun 2014 oleh Dinas kesehatan Kebuapten Aceh Singkil. Pelatihan juga diberikan kepada Analis (petugas laboratorium) untuk mengetahui apakah pasien positif menderita malaria. 
Pelatihan bertujuan agar petugas malaria dapat menigkatkan kemampuan dan keteram-pilan dalam menjalan program malaria. jika pelatihan tidak dilakukan refresing dapat membuat kualitas kerja petugas menjadi menurun (Khayati, Yuliawati, \& Wuryanto, 2012).

Namun kegiatan tersebut ini tidak berlangsung sampai saat ini karena diduga cukup dideskrip petugas sudah mampu dan terampil dalam penanganan program malaria. Padahal jika kemampuan dan keterampilan tidak diasah (refresing) atau dipraktekkan, kemampuan petugas dapat menurun dan bahkan tugas dan tanggung jawabnya dalam program malaria tidak optimal.

\section{KESIMPULAN DAN SARAN}

\section{Kesimpulan}

1. Kegiatan penemuan dan tata laksana penderita mulai berkuang dan pengobatan jua tidak pernah dilakukan karena kasusnya tidak ditemukan lagi.

2. Pendistribusian kelambu penyemprotan, skrining ibu hamil frekuensi berkurang dan pengendalian vektor hayati tidak dipantau.

3. Kegiatan surveilans epidemiologi dan penanggulangan wabah hanya berupa bentuk laporan saja yang rutin di sampaikan petugas puskesmas ke dinas.
4. Kegiatan penyuluhan kepada masyarakat berfokus pada kader desa dan kegiatan pertemuan kemitraan/ koordinasi diselenggarakan setiap akhir tahun.

5. Kegiatan pelatihan/sosialisasi tidak pernah diselenggarakan.

\section{Saran}

1. Dinas Kabupaten Aceh Singkil diharapkan tetap waspada dan tetap memprioritas program mendukungan program eliminasi malaria melalui pemberdayaan masyarakat.

2. Diharapkan kerjasama sama lintas program dan sektoral berkomitmen mempertahankan eliminasi malaria di daerah masing-masing dengan tetap memberikan penyuluhan berupa himbauan waspada malaria kepada masyarakat.

3. Masyarakat diharapkan tetap menjaga kebersihan lingkungan dan perilaku hidup bersih dan sehat (PHBS) dan aktif mengikuti kegiatan gotong royong Jumat Bersih serta program 3M memutus rantai perkembangbiakan nyamuk malaria.

\section{DAFTAR PUSTAKA}

Aceh, P. (2015). Profil Kesehatan Provinsi Aceh. Banda Aceh.

Akay, C. S., Tuda, J. S. B., \& Pijoh, V. D. (2015). Gambaran Pengetahuan Masyarakat Tentang Penyakit Malaria Di Kecamatan Silian Raya Kabupaten Minahasa Tenggara. Jurnal E-Biomedik, 3(1). https://doi.org/10.35790/ebm.3.1.2 
015.7421

Irawan, A. S., Pujiyanti, A., \& Trapsilowati, W. (2014). Pengetahuan dan Perilaku Komunitas Mengenai Malaria Di Daerah Kejadian Luar Biasa Malaria Kecamatan Rowokele , Kabupaten Kebumen: Perspektif Ethnosains (Community Knowledge and Attitude on Malaria in Outbreak Area Rowokele Subdistrict , Kebumen Regency. Buletin Penelitian Sistem Kesehatan, 17(4), 363-370.

Kemenkes. (2013). Hari Malaria Sedunia di Indonesia. Jakarta: Kemenkes RI.

Kemenkes. (2014). Pedoman Penatalaksanaan Kasus Malaria di Indonesia. Jakarta: Kemenkes RI.

Khayati, N., Yuliawati, S., \& Wuryanto, M. A. (2012). Apriana Kurniati Alumnus Fakultas Kesehatan Masyarakat UNDIP (c) 2012. Beberapa Faktor Petugas yang Berhubungan dengan Pelaksanaan Surveilans Epidemiologi Malaria Tingkat Puskesmas di Kabupaten Purworejo Nur, 1, 364-373.

Laihad FJ, Harijanto P, P. J. (2011). Epidemiologi Malaria di Indonesia. Jakarta: Kemenkes RI.

Ngambut, K., \& Sila, O. (2013). Faktor Lingkungan dan Perilaku Masyarakat Tentang Malaria di Kecamatan Kupang Timur Kabupaten Kupang. Kesmas: National Public Health Journal, 7(6), 271. https://doi.org/10.21109/kesmas.v7 i6.37.

Renwarin, V. M. V, Kandou, J. M. L., \& D, U. G. (2014). Analisis Pelaksanaan Program Eliminasi Malaria di Kota Tomohon. Jikmu, 4(4), 634-643.

Rogayah, H., Mahendradhata, Y., Padmawati, R. S., Kebijakan, P., Kesehatan, P., \& Ugm, F. K. (2015). Evaluasi Program Terpadu Pengendalian Malaria, Evaluation Of Integrated Malaria Control Program, Maternal Health Care
And pelayanan ibu hamil dan imunisasi juga diimplemen-. 04(01), 26-31.

Salman, A., Pinontoan, O. R., \& Keeknusa, J. (2017). Eevaluasi Pelaksanaan Proram Eliminasi Malaria Di Kabupaten Halmahera Timuror. Community Health, 2, No. 5, 106-117. Retrieved from http://www.ejournalhealth.com/ind ex.php/CH/article/view/626/614.

Selasa, P. (2017). Implementation of Malaria Elimination Policy at Kupang City Public Health Center Implementasi Kebijakan Eliminasi Malaria di Pusat Kesehatan Masyarakat Kota Kupang. Jurnal Info Kesehatan, 15(1), 97-109.

Singkil, P. K. A. (2018). Profil Dinas Kesehatan Tahun 2017. Singkil.

WHO. (2019). World Malaria Report.

Zaenuddin, \& Hendrati, L. Y. (2014). Evaluasi pelaksanaan sistem surveilans malaria di Dinas Kesehatan Kabupaten Sumbawa Besar. Jurnal Berkala Epidemiologi, 2(3), 342-354. 